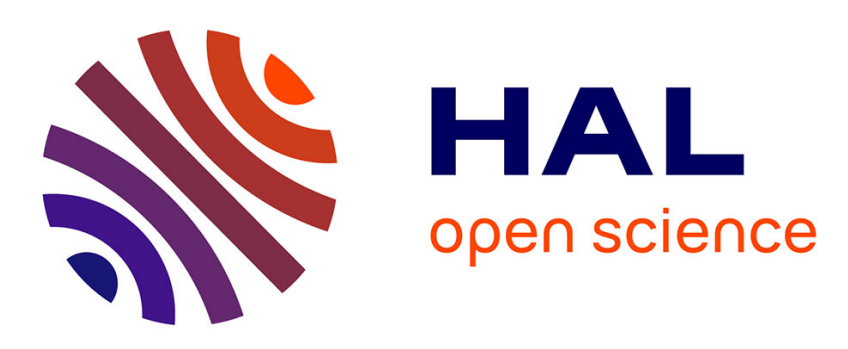

\title{
The Teaching of Engineers Focused on Innovative Entrepreneurship
}

\author{
Danielle Miquilim, Marcia Terra da Silva
}

\section{To cite this version:}

Danielle Miquilim, Marcia Terra da Silva. The Teaching of Engineers Focused on Innovative Entrepreneurship. IFIP International Conference on Advances in Production Management Systems (APMS), Sep 2019, Austin, TX, United States. pp.425-432, 10.1007/978-3-030-30000-5_53 . hal02419231

\section{HAL Id: hal-02419231 \\ https://hal.inria.fr/hal-02419231}

Submitted on 19 Dec 2019

HAL is a multi-disciplinary open access archive for the deposit and dissemination of scientific research documents, whether they are published or not. The documents may come from teaching and research institutions in France or abroad, or from public or private research centers.
L'archive ouverte pluridisciplinaire HAL, est destinée au dépôt et à la diffusion de documents scientifiques de niveau recherche, publiés ou non, émanant des établissements d'enseignement et de recherche français ou étrangers, des laboratoires publics ou privés. 


\title{
The Teaching of Engineers focused on Innovative Entrepreneurship
}

\author{
Miquilim, Danielle $\mathrm{e}^{1[0000-0001-5143-6590]}$ and Terra da Silva, Marcia ${ }^{2[0000-0002-5314-4978]}$ \\ ${ }^{1}$ Universidade Paulista, São Paulo, Brazil \\ miquilimehotmail.com \\ ${ }^{2}$ Universidade Paulista, São Paulo, Brazil \\ marcia.terra@uol.com.br
}

\begin{abstract}
Engineering schools have a traditional way of teaching based on a sequence of subjects, beginning with fundamental sciences, mathematics, technologies and finally exploring practice and technics. This kind of program allows to deepen each subject, however, hinders the perception of the connections among the parts of a problem. Some schools changed their course aiming to turn the program more attractive to the students and, at the same time, more focused on the solution of actual problems the professionals face. For that, they used an innovative entrepreneurship approach changing the teaching-learning process. This article aims to identify the factors necessary to implement an innovative entrepreneurial engineering education, as well as explain such factors through literature review. As a result, two major categories of factors are observed, the teaching-learning process and university management. The first one encompasses the role of teachers, students, curriculum, and extracurricular activities. The literature suggests an open speech among students and teachers where they can explore multiple and critical perspectives. The PBL (ProjectBased Learning) is recommended as a teaching-learning process. Extracurricular activities like scientific initiation, Incubators, and patents are other factors that contribute to this type of teaching. In university management, the incentive to innovation in engineering education is strongly recommended, besides providing students and teachers with an infrastructure that supports research and development and deployment of organizational culture and structure focusing on innovative entrepreneurship.
\end{abstract}

Keywords: Professional Service Management. University Management Engineering Education. Entrepreneurship.

\section{Introduction}

Good quality engineering education and regional development go together [1], and, with the rapid evolution of technology, an essential feature of the teaching of this professional becomes flexibility, so that the teaching adapts to the new knowledge, techniques, and demands of the market. 
Nowadays, job market calls for an innovative professional with a solid basis in mathematics and science, as well as management knowledge, capable of the selfdevelopment of technical and transversal skills [2]. However, traditional education prepares engineers with strong technical knowledge, without a focus on management skills or the ability to learn autonomously. Besides, many students do not fit the course and interrupt it, producing a high rate of drop out in engineering programs.

Because of this problematic, many engineering schools became interested in courses driven to form engineers-entrepreneurs innovative and proactive [3]. The entrepreneurship programs are based on multidisciplinary interaction, teamwork, and communication. Over time students acquire the basics of engineering, gain perceptions of the business management process, and learn about ethical decisions, leadership, communication, and problem-solving [4]. In addition to these existing entrepreneurship programs, several schools, less evident, practice this experience in a timely, isolated and unshared way. These attitudes are individualized, in the hands of some teachers or a coordinator who believe in the results, but who do not know how to implement it fully.

This article aims to identify in the literature the factors of the teaching-learning process recommended to breed innovative entrepreneur engineers and also, the features of university management that facilitate or hinder the implementation of such education. The teaching-learning process is decoupled in essential elements, involving the teachers-pupils relationship, the teaching material, methodology, and organization of education. University management, instead, refers to the strategy, actions, and control of the results that the educational institution decides to accomplish. We assumed that management should be consistent with the teaching model.

\section{$2 \quad$ Methodology}

Initially, a review of the literature on innovative entrepreneurial engineering education was conducted, following the process of performing systematic revisions [5]. The characteristics of this systematic revision are the definition of the revision protocol; the establishing of a search strategy that seeks to detect as much relevant literature as possible; documented search strategy so that readers can assess seriousness and completeness; inclusion and exclusion criteria to evaluate each study. The main goal of the review was obtaining information to help to identify the factors that characterize an innovative entrepreneurial engineering school.

As a starting point, four university rankings are examined: the THE (Times Higher Education), the CWUR (Center for World University Rankings), the QS World University Rankings, and the RUF (Ranking of Universities of Folha*). The rankings provided a new view of the engineering schools' assessment process.

After the analysis of the rankings, we searched in academic journals the factors of an innovative entrepreneurial engineering school considering two perspectives: teaching-learning process and the university management. As sources of research, Google Scholar, Web of Science and Science Direct were used. In the search, the following descriptors were used in Portuguese and English language: "Innovative Entrepreneur- 
ship", "Higher education "," Engineering "," University Management "and" TeachingLearning Process ". The "AND", "OR" and "AND NOT" logical operators were used for the combination of the descriptors and terms for tracing the publications. The period set for the data collection ranges from 2010 to 2017.

After that, we evaluated the abstracts, the studies that seemed to fill the inclusion criteria were read in full. In the end, 108 articles met all the inclusion criteria. Then, the following aspects were observed: period and place of publication; author; definitions, characteristics of the study; evaluated conclusions; the journal in which the study was published (classified according to JCR Impact Factor). The extraction of data from the articles was made by the authors and consolidated in a model that suggests characteristics of an innovative entrepreneurial engineering school.

\section{Results}

In this study, it was observed that the literature examined the factors that characterize innovative engineering schools each at a time, separated from other factors, mainly when we refer to the teaching-learning process. The teaching-learning process can be understood as the producing process of an engineering school and encompasses the sequence of activities, the method, and material required, the professional role, and the students' activities.

\subsection{Teaching and Learning Process}

The search containing "Teaching-learning" returned 6,858 papers. Below, figure 1 shows the number of articles over the years, and we can see that the interest in the subject is stable from 2011 to 2016, with on average almost 1,000 publications per year.

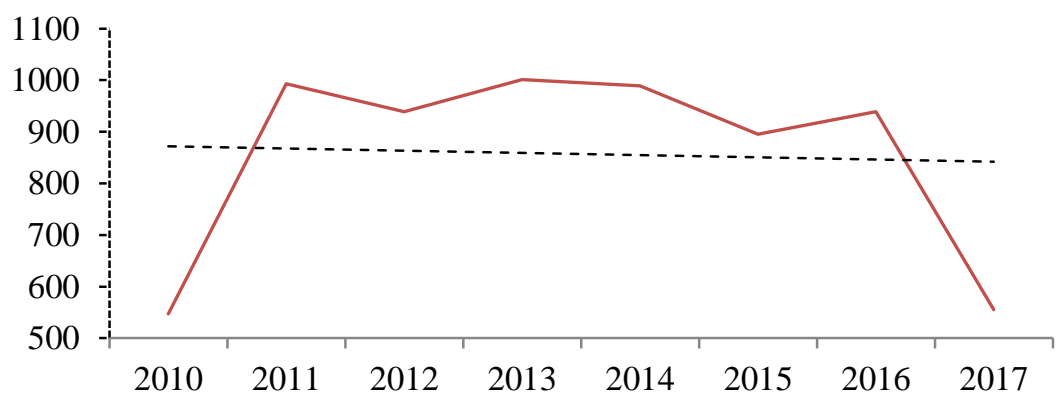

Fig. 1. Number of publications concerning the teaching-learning process over the years.

The teaching method undergoes a radical change from the traditional methods of teaching, which tend to focus on the transfer of knowledge, and emphasize individual work to project-based learning which promotes the teamwork and proactive learning, 
seeking solutions and decision making for the proposed problems. The traditional pedagogical methods are lessons, tests, and written works, while the collected literature recommends for this teaching approach simulation of business, games, development of companies or virtual or real products, visits to companies and entrepreneurs and the elaboration of a business plan [6].

The teacher's attitude is an essential factor to implement the new teaching methodologies and induce the integration of other disciplines. Also, it is up to the teachers to stimulate students to think and act with an entrepreneurial mindset, not conforming to reality, focusing on innovation, with the courage to take risks and experience of market [7].

The changing in the teaching methods also demands a change in the role of the student. Some authors maintain that innovative entrepreneurial education should be focused on the student, who is responsible for learning in an experimental, practical and contextualized way, as this encourages imagination and analysis, preparing the student to deal with uncertainty and lack of resources and preparing them to an innovation process scenario [8].

As for the curriculum, researched authors [9], [10] observed that the engineering school should include specific disciplines related to innovative entrepreneurship and to promote the interdisciplinarity so that the student can have an integrated frame to approach the problems. The engineering curriculum should also balance the development of human skills in the same intensity of their necessary technical skills [11]. The challenge of such programs stays in developing the skills in areas such as negotiation, leadership, creativity, technological innovations, and new product development. Given this, the education of an innovative engineer should not be seen as a separate discipline, but as a set of actions whereby students are instructed to expand their ideas and that this process should be established from the first periods of graduation [12].

Another key issue identified is the extracurricular activities, as the insertion of incubators, student organizations and junior companies, that provide infrastructure and support for microentrepreneurs and accelerate the student's entrepreneur potential [13].

\subsection{University Management}

The second perspective analyzed is university management, which facilitates and stimulates the teaching-learning process, consistent with an innovative entrepreneurial vision. The 2,059 articles collected examine the following factors: strategy, culture and organizational structure, leadership, and internationalization. Fig. 2 shows that there is an increasing rate of publications on this subject, reaching its peak in the years 2015 and 2016, which represented the most productive period in publications. 


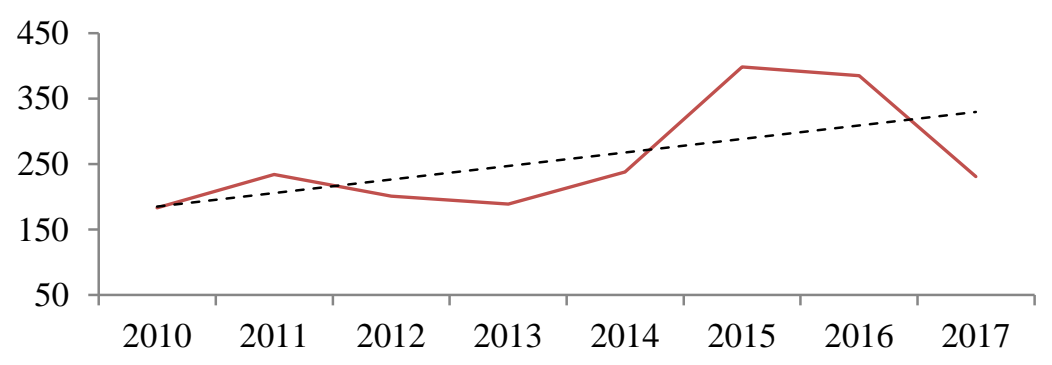

Fig. 2. Number of publications about university management over the years

The formation of strategies in an engineering school is a complex management process, mainly because of the high unpredictability and uncertainties of the external environment. Also, the structure is loosely articulated as in organizations where professional experts develop the essential operational work. [14].

Higher education institutions have a very broad, ambiguous and intangible mission, which makes it challenging to define and operationalize objectives; planning in these institutions is an isolated and random activity since it works by short-term budget cycles and aims long-term results. Their professionals work independently, motivated by personal objectives, making it difficult for analysts to rationalize structures from their abilities. Higher education institutions have no managerial skills to make rapid changes; their lines of authorities are unclear; their leaders work as catalysts: do not command, but negotiate, they do not plan broadly either solve problems using preexisting solutions; changes depend on the consensus and the authority of a lot of people [15].

In this way, the main challenge for the management of this type of school is to create an environment conducive to the emergence of entrepreneurs. That points out the need for an integrating organizational culture that can contribute to the development of new ideas and new strategies that cross the boundaries of structures. The entrepreneurial culture is a culture in which entrepreneurship is embraced by the majority, if not by all; therefore, the values belonging to the institution should be shared by people at different levels of the higher education institutions hierarchy. In an entrepreneurial culture, people can deal with risk and respond to fast context change, helping innovation process. [16], [17]. Accordingly, the organizational structure must support secure communication among the various specialties, promoting the multidisciplinary of the curriculum.

Also, the University internationalization is an essential factor for the development of the students' entrepreneur skills, as primarily mentioned in the literature. [17]. On the one hand, the internationalization allows the student to experience different curriculum models at several levels, as student organizations, incubators, and agencies that promote innovative entrepreneurship. On the other hand, the process of integration abroad, regarding creating organizational bonds and support, can immensely contribute to the student creation of a new vision of social interactions, strengthening innovative entrepreneurial education [16]. 
Finally, internationalization can be defined as the crossing of cultural frontiers [18] and adds significantly to the innovative entrepreneurial teaching style. It occurs not only when the students go abroad, but also when the school receives international classmates. The teaching-learning process and the extracurricular activities with multicultural groups also strengthen the ability to innovate, giving them new tools to solve problems, aspects so important to entrepreneurs. [19].

\section{Discussion}

Entrepreneurship and innovation depend on an ecosystem of interrelated elements [20]. An innovative entrepreneurial ecosystem is defined as an environment endowed with agents (markets, policies, finance, culture, support, and human capital) that contribute to the development of innovation and entrepreneurship through their interactions. One class of agents by itself cannot modify the system, only with the support of other groups of agents it is possible to create a climate favorable to innovation and entrepreneurship, what eventually results in the creation of new markets, jobs, revenue streams, and innovation.

Based on the concept of ecosystem, we believe that an innovative engineering school has to be analyzed considering several factors, which are divided into two views. The first perspective is connected to the learning process, which encompasses the operational elements of an educational institution, that is, presents the most critical factors that contribute for students to acquire knowledge and skills necessary for their profession (role of the teacher, the role of the pupil, curriculum and extracurricular activities). The second perspective represents the university management, which should provide factors that will contribute to good governance in innovative entrepreneurial engineering schools. Infrastructure, strategy, culture and organizational structure, internationalization and leadership are the main management factors for this type of teaching.

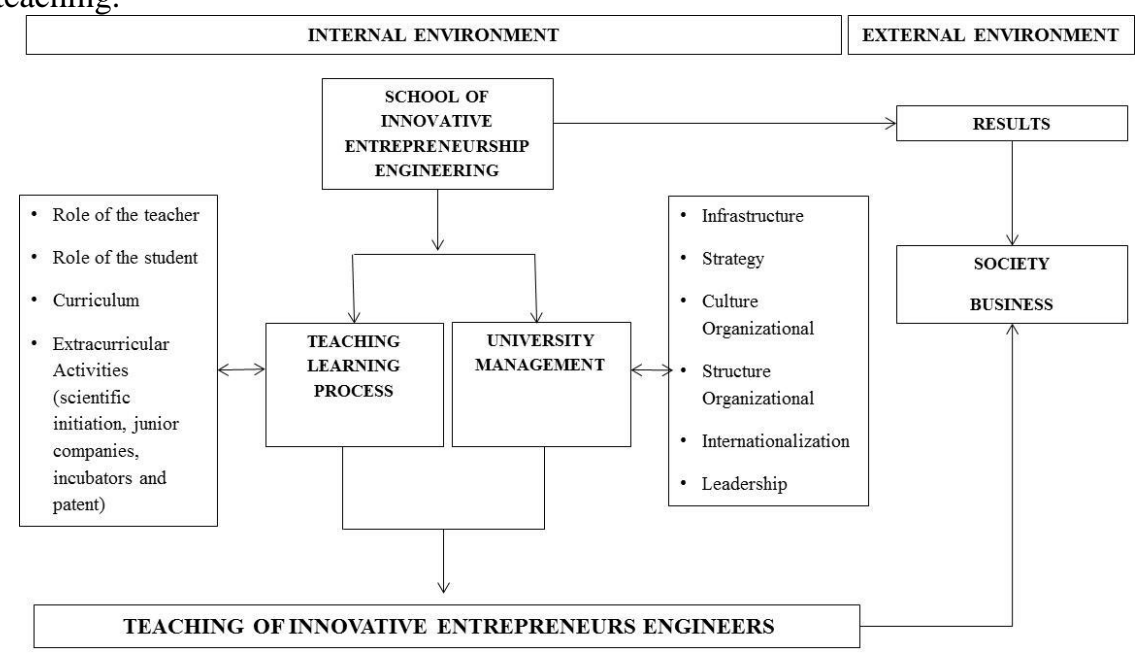

Fig. 3. Driving factors for the Innovative Entrepreneur Engineer Education 


\section{Conclusion}

Our starting point in this article is the understanding of what the job market expects of the future engineer. The job market seeks engineers with a broad vision, a business vision, beyond the technical view. For this to happen, engineering schools need to manage and teach in a different way.

The implications of this concept, both for the school and for the teachers and engineering students, represent a new responsibility, a new culture, a new form of managing, teaching, and learning. Directors, coordinators, teachers, and students must practice the innovative entrepreneurship in daily activities, not only in classrooms or as an academic subject.

A contribution of this research is the identification of a literature gap on research that links the university management to the entrepreneurial teaching-learning process. Studies focusing on teaching-learning factors and management factors in a connected way were not found.

Furthermore, one of the relevant results pointed out by this bibliographical review is that while the publications about the teaching-learning process maintain a constant number over the years, the number of articles on University management has increased from 2010 to 2017 . Nevertheless, a change in the management system should not be seen without considering its impact on the teaching-learning process. For that reason, this article defends that both subjects should be faced as parts of the learning ecosystem, and consequently, they should be complementary.

\section{References}

1. Caldana, V.M., Silva, M.T. da: Regional development and engineering education: an analysis of Brazil's micro-regional scenario. Production. 27, (2017). doi:10.1590/0103-6513.225016

2. Eduardo, G., Battisti, S., Rafael, P., Traverso, P.: High impact drivers in innovation ecosystems: the case of Tecnopuc-Fbk joint lab. Presented at the VII Congresso Internacional de Conhecimento e Inovação (ciKi) (2017)

3. Daly, S.R., Mosyjowski, E.A., Seifert, C.M.: Teaching Creativity in Engineering Courses. J. Eng. Educ. 103, 417-449 (2014). doi:10.1002/jee.20048

4. FILA, N.: Evaluation Of Current Assessment Methods In E- ngineering Entrepreneurship Education. Entrepreneurship Education. 27 (2016)

5. Kitchenham, B.: Procedures for Performing Systematic Reviews. 33

6. Englund, C., Olofsson, A.D., Price, L.: Teaching with technology in higher education: understanding conceptual change and development in practice. Higher Education Research \& Development. 36, 73-87 (2017). doi:10.1080/07294360.2016.1171300

7. Stough, T., Ceulemans, K., Lambrechts, W., Cappuyns, V.: Assessing sustainability in higher education curricula: A critical reflection on validity issues. Journal of Cleaner Production. 172, 4456-4466 (2018). doi:10.1016/j.jclepro.2017.02.017 
8. Lucia, Ó., Burdio, J.M., Acero, J., Barragán, L.A., Garcia, J.R.: Educational opportunities based on the university-industry synergies in an open innovation framework. European Journal of Engineering Education. 37, 15-28 (2012). doi:10.1080/03043797.2011.644762

9. Lozano, F.J., Lozano, R.: Developing the curriculum for a new Bachelor's degree in Engineering for Sustainable Development. Journal of Cleaner Production. 64, 136-146 (2014). doi:10.1016/j.jclepro.2013.08.022

10. Xu, Y., Wang, L., Wang, S., Liu, M.: An effective teaching-learning-based optimization algorithm for the flexible job-shop scheduling problem with fuzzy processing time. Neurocomputing. 148, 260-268 (2015). doi:10.1016/j.neucom.2013.10.042

11. Korsgaard, S., Müller, S., Tanvig, H.W.: Rural entrepreneurship or entrepreneurship in the rural - between place and space. Int Jrnl of Ent Behav \& Res. 21, 5-26 (2015). doi:10.1108/IJEBR-11-2013-0205

12. Subudhi, R., Das, B.: Professional Education for Employability: A Critical Review. Social Science Research Network, Rochester, NY (2015)

13. Sivard, G., Shariatzadeh, N., Lindberg, L.: Engineering Innovation Factory. Procedia CIRP. 25, 414-419 (2014). doi:10.1016/j.procir.2014.10.057

14. Petrova, G.I., Smokotin, V.M., Kornienko, A.A., Ershova, I.A., Kachalov, N.A.: Knowledge Management as a Strategy for the Administration of Education in the Research University. Procedia - Social and Behavioral Sciences. 166, 451-455 (2015). doi:10.1016/j.sbspro.2014.12.552

15. Zhang, Z., Zyphur, M.J., Narayanan, J., Arvey, R.D., Chaturvedi, S., Avolio, B.J., Lichtenstein, P., Larsson, G.: The genetic basis of entrepreneurship: Effects of gender and personality. Organizational Behavior and Human Decision Processes. 110, 93-107 (2009). doi:10.1016/j.obhdp.2009.07.002

16. Kautonen, T., Down, S., Minniti, M.: Ageing and entrepreneurial preferences. Small Bus Econ. 42, 579-594 (2014). doi:10.1007/s11187-013-9489-5

17. Liñán, F., Fernandez-Serrano, J.: National culture, entrepreneurship and economic development: different patterns across the European Union. Small Bus Econ. 42, 685-701 (2014). doi:10.1007/s11187-013-9520-x

18. Boddewyn, J.J., Toyne, B., Martinez, Z.L.: The Meanings of "International Management.” MIR: Management International Review. 44, 195-212 (2004)

19. Philip G. Altbach, Jane Knight: The Internationalization of Higher Education: Motivations and Realities. Journal of Studies in International Education. 11, 290-305 (2007). doi:10.1177/1028315307303542

20. Stam, E.: Entrepreneurial Ecosystems and Regional Policy: A Sympathetic Critique. European Planning Studies. 23, 1759-1769 (2015). doi:10.1080/09654313.2015.1061484

21. Kirkley, W.W.: Entrepreneurial behaviour: the role of values. Int Jrnl of Ent Behav \& Res. 22, 290-328 (2016). doi:10.1108/IJEBR-02-2015-0042 